\title{
Efficacy and safety of capecitabine-based first-line chemotherapy in advanced or metastatic breast cancer: a meta-analysis of randomised controlled trials
}

\author{
Weijiao Yin ${ }^{1, *}$, Guangsheng Pei ${ }^{2, *}$, Gang Liu ${ }^{1}$, Li Huang ${ }^{3}$, Shegan Gao ${ }^{1}$, Xiaoshan Feng ${ }^{1}$ \\ ${ }^{1}$ Department of Oncology, the First Affiliated Hospital of Henan University of Science and Technology, Luoyang, PR, China \\ ${ }^{2}$ Department of Respiratory Medicine, the First Affiliated Hospital of Henan University of Science and Technology, Luoyang, \\ $\mathrm{PR}$, China \\ ${ }^{3}$ Department of Gynecology, the First Affiliated Hospital of Henan University of Science and Technology, Luoyang, PR, China \\ *These authors have contributed equally to this work \\ Correspondence to: \\ Xiaoshan Feng, e-mail: everbei@hotmail.com \\ Shegan Gao, e-mail: shikelangtian@sina.cn \\ Keywords: capecitabine, breast cancer, first-line, meta-analysis \\ Received: July 09, $2015 \quad$ Accepted: September 18, 2015 \\ Published: September 30, 2015
}

\section{ABSTRACT}

We sought to evaluate the efficacy and safety of capecitabine-based therapy as first-line chemotherapy in advanced breast cancer. Randomised controlled trials of capecitabine monotherapy or combined treatment were included in the meta-analysis. PubMed, EMBASE, the Cochrane Library database and important meeting summaries were searched systematically. Outcomes were progression-free survival (PFS), overall survival (OS), overall response rate (ORR) and grades 3-4 drug-related adverse events.

Nine trials with 1798 patients were included. The results indicated a significant improvement with capecitabine-based chemotherapy compared with capecitabinefree chemotherapy in ORR (relative risk [RR] 1.14, 95\% confidence interval [CI] 1.03 to $1.26, P=0.013$ ) and PFS (hazard ratio [HR] $0.77,95 \% \mathrm{CI} 0.69$ to $0.87, P<$ 0.0001 ). Overall survival favoured capecitabine-based chemotherapy, but this was not significant. There were more incidences of neutropenia and neutropenic fever in the capecitabine-free chemotherapy group and more vomiting, diarrhoea and hand-foot syndrome in the capecitabine-based chemotherapy group. There were no significant differences in nausea, fatigue, cardiotoxicity or mucositis/stomatitis between the two treatment regimens.

Capecitabine-based chemotherapy significantly improves ORR and PFS in patients with advanced breast cancer, but has no demonstrable impact on OS. Capecitabine-based regimens are suitable as first-line treatment for patients with advanced breast cancer.

\section{INTRODUCTION}

Breast cancer remains the most common cancer among women worldwide. Despite significant improvements in survival outcomes over the past two decades, breast cancer remains the leading cause of cancer death in developing countries and the second in developed countries $[1,2]$. The main goals of treatment of advanced breast cancer are to optimise length and quality of life. Approximately 16-20\% of women with breast cancer have advanced or metastatic disease, and $50 \%$ of early stage breast cancers ultimately develop into metastatic breast cancer [1]. It is reported that advanced breast cancer contributes significantly to cancer mortality among women. Patients with advanced breast cancer do not have the option of surgical cure. Even so, the use of chemotherapy after surgery results in a significant reduction in systemic recurrence in patients with isolated loco-regional recurrences [3]. Anthracycline and taxane-based regimens are standard chemotherapy for advanced breast cancer or metastatic breast cancer. However, anthracycline-induced cardiotoxicity limits its application in widespread clinical practice [4]. 
Capecitabine is an oral pro-drug of 5'-deoxy-5fluorouridineat. It shows strong anti-tumour activity in tumour cells and is well tolerated. Capecitabine has been approved as combination chemotherapy or monotherapy for the treatment of patients with locally advanced or metastatic breast cancer after failure of anthracycline- and taxane-based chemotherapy [5-7]. A series of clinical studies demonstrated that capecitabine improved overall survival and response rates in firstline chemotherapy against advanced breast cancer $[8,9]$. The aim of this current analysis is to evaluate the efficacy and safety of capecitabine-based chemotherapy as first-line treatment in advanced breast cancer or metastatic breast cancer.

\section{RESULTS}

A total of 377 articles related to the analysis were found from the literature and subjected to the selection process (Figure 1). Finally, nine randomised controlled trials with 1798 patients met the inclusion criteria and were included in the meta-analysis [8, 9, 12-18]. The baseline characteristics of the included studies are listed in Table 1. Of the nine articles, six were of capecitabine combination therapy and three were of capecitabine monotherapy versus other chemotherapy.

\section{Overall response rate}

Eight trials reported the outcome of ORR and 1692 patients were included in the analysis. The pooled analysis of ORR showed that there was a significant improvement with capecitabine-based chemotherapy compared with capecitabine-free chemotherapy in the treatment of advanced or metastatic breast cancer (RR $1.14,95 \%$ CI 1.03 to $1.26, P=0.013$ ) (Figure 2). A fixed-effect model was used because no significant heterogeneity was found between the trials $\left(\mathrm{I}^{2}=0.0 \%\right.$, $P=0.435)$.

\section{Progression-free survival}

Data for PFS were available from eight trials. The pooled HR for PFS demonstrated that capecitabinebased chemotherapy was associated with significantly longer PFS when compared with capecitabine-free chemotherapy as first-line treatment for the patients with advanced or metastatic breast cancer (HR 0.77, 95\% CI 0.69 to $0.87, P<0.0001$ ) (Figure 3). A random-effects model was used because significant heterogeneity was found between the trials $\left(\mathrm{I}^{2}=56.3 \%\right.$, $P=0.025)$.

\section{7 articles indentified in research}

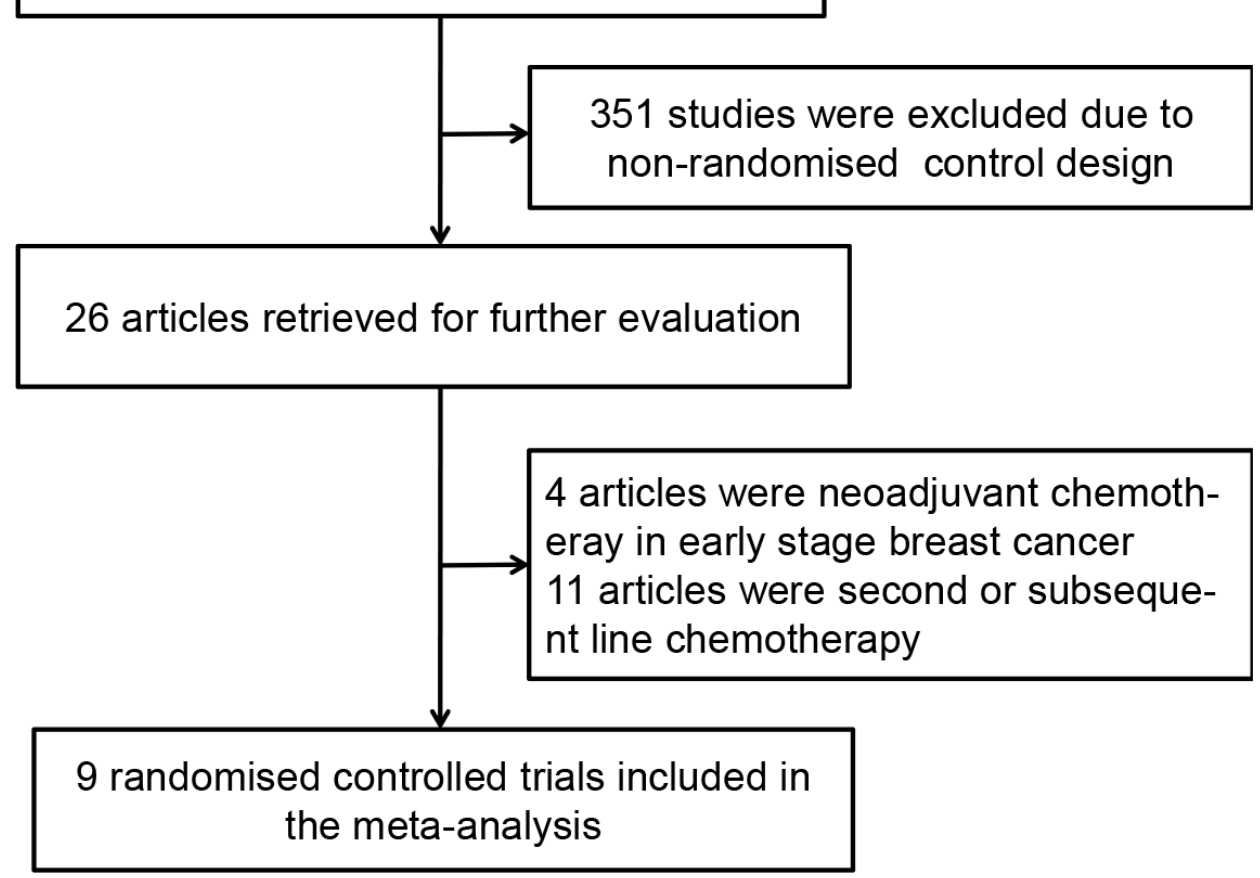

Figure 1: Flow diagram of the process of selecting randomised controlled trials. 
Table 1: The main characteristics of RCTs included in the meta-analysis

\begin{tabular}{|c|c|c|c|c|c|}
\hline Author & Year & Trail phase & Treatment regimens & No. of patients & Median follow-up duration \\
\hline \multirow[t]{2}{*}{ Smorenburg $\mathrm{CH}$} & 2014 & III & CAP & 38 & 39.0 months \\
\hline & & & PLD & 40 & \\
\hline \multirow[t]{2}{*}{ Lam SW } & 2014 & II & $\mathrm{TAX}+\mathrm{BEV}+\mathrm{CAP}$ & 156 & 41.2 months \\
\hline & & & $\mathrm{TAX}+\mathrm{BEV}$ & 156 & \\
\hline \multirow[t]{2}{*}{ Lück HJ } & 2013 & III & $\mathrm{TAX}+\mathrm{CAP}$ & 169 & 24.9 months \\
\hline & & & TAX+EPI & 170 & \\
\hline \multirow[t]{2}{*}{ Vici P } & 2011 & II & $\mathrm{DOC}+\mathrm{CAP}$ & 36 & Not stated \\
\hline & & & $\mathrm{DOC}+\mathrm{GEM}$ & 36 & \\
\hline \multirow[t]{2}{*}{ Stockler MR } & 2011 & III & CAP & 216 & 39.6 mouths \\
\hline & & & $\mathrm{CMF}$ & 109 & \\
\hline \multirow[t]{2}{*}{ Bachelot T } & 2011 & III & $\mathrm{DOC}+\mathrm{CAP}$ & 33 & 42.0 months \\
\hline & & & DOC+EPI & 35 & \\
\hline \multirow[t]{2}{*}{ Wardley AM } & 2010 & II & $\mathrm{TRA}+\mathrm{DOC}+\mathrm{CAP}$ & 113 & 24.0 months \\
\hline & & & $\mathrm{TRA}+\mathrm{DOC}$ & 112 & \\
\hline \multirow[t]{2}{*}{ Mavroudis D } & 2010 & III & $\mathrm{DOC}+\mathrm{CAP}$ & 145 & 43.8 months \\
\hline & & & $\mathrm{DOC}+\mathrm{EPI}$ & 141 & \\
\hline \multirow[t]{2}{*}{$\begin{array}{l}\text { O'Shaughnessy } \\
\text { JA }\end{array}$} & 2001 & II & CAP & 61 & Not stated \\
\hline & & & CMF & 32 & \\
\hline
\end{tabular}

Abbreviations: RCTs, randomised controlled tirals; CAP, capecitabine; PLD, pegylated liposomal doxorubicin; TAX, paclitaxel; BEV, bevacizumab; EPI, epirubicin; DOC, docetaxel; GEM, gemcitabine; CMF, cyclophosphamide, methotrexate and fluorouracil

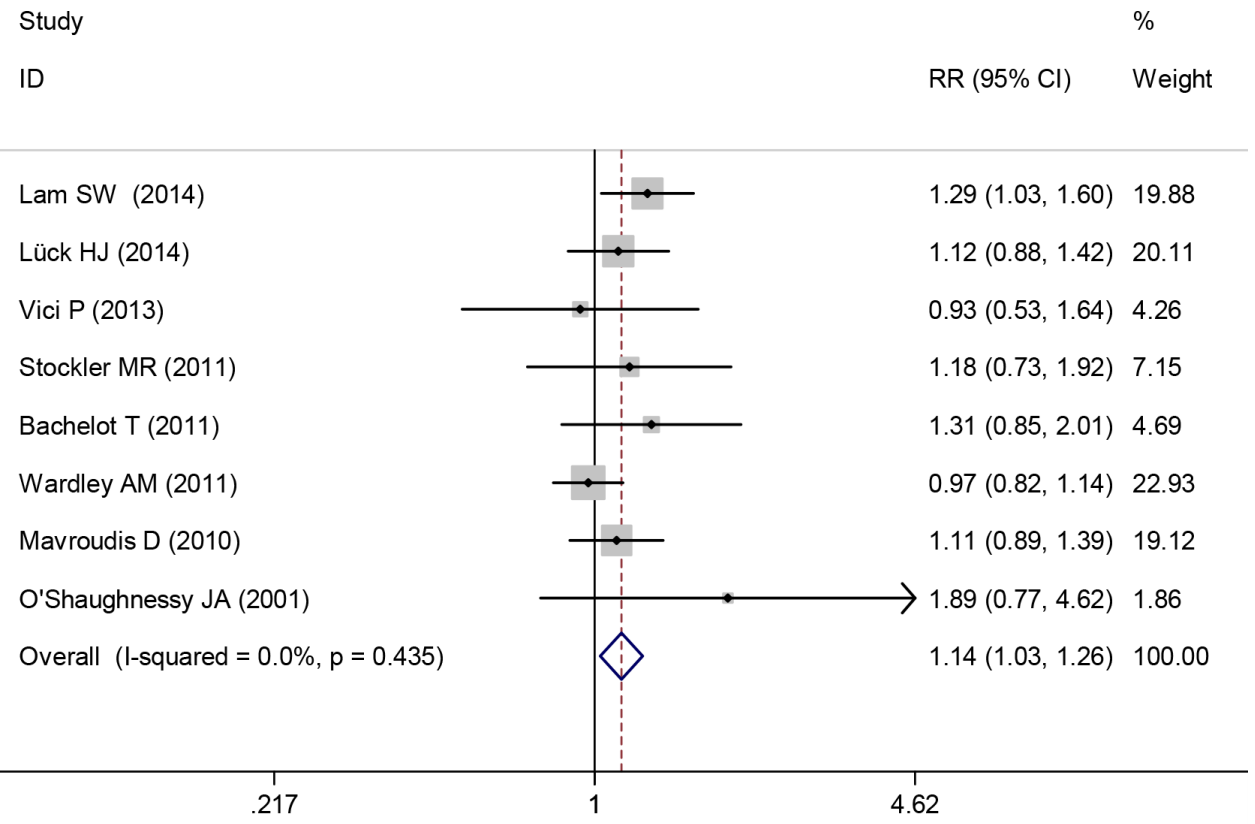

Figure 2: Overall response rate of capecitabine-based chemotherapy versus capecitabine-free chemotherapy. 


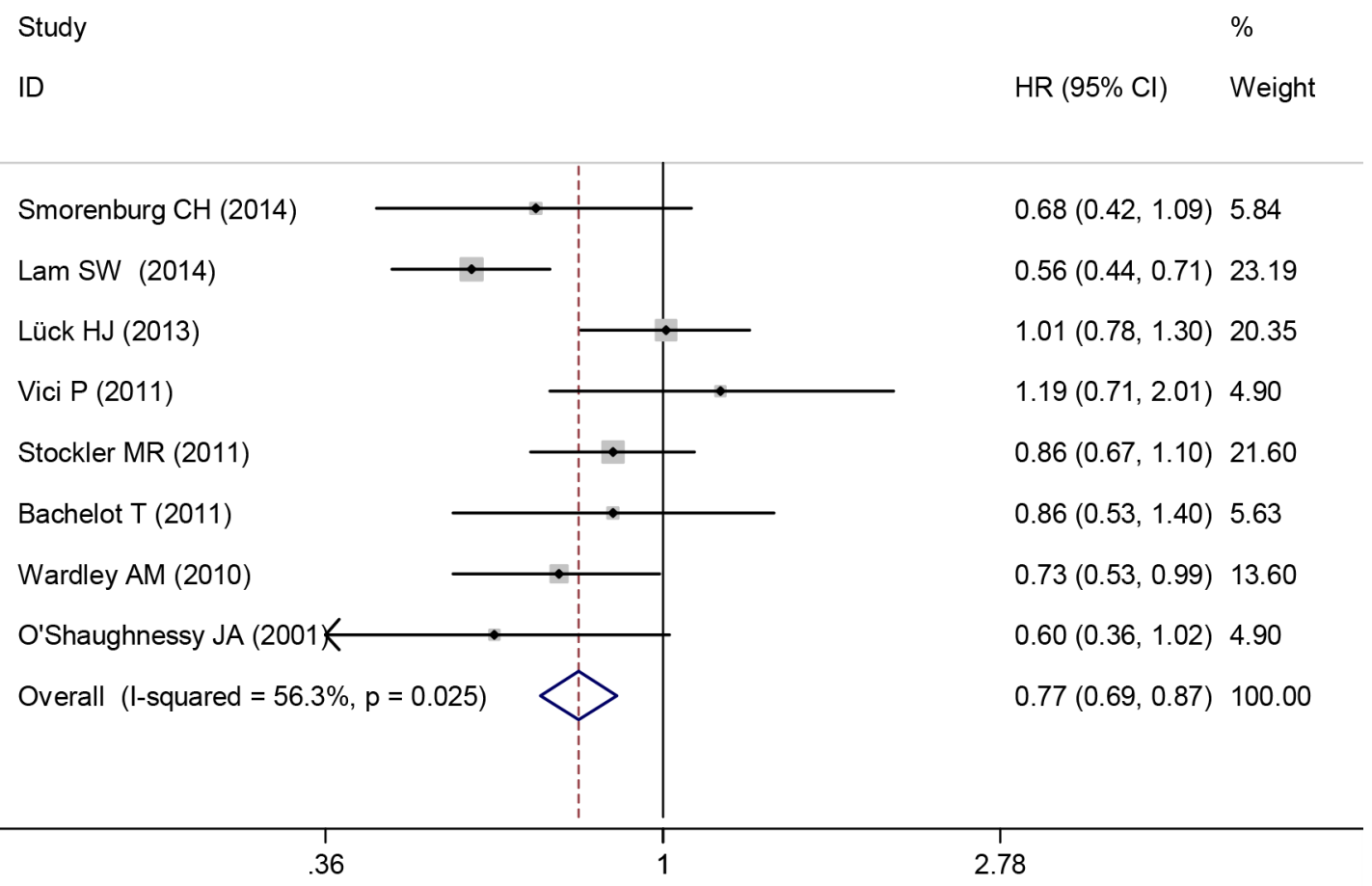

Figure 3: Progression-free survival of capecitabine-based chemotherapy versus capecitabine-free chemotherapy.

\section{Overall survival}

Eight trials reported the HR for OS of advanced or metastatic breast cancer. Capecitabine-based therapy did not show a significant advantage over capecitabinefree chemotherapy. The pooled HR indicated that there was no significant difference in OS between the groups of capecitabine-based chemotherapy and capecitabinefree chemotherapy (HR $0.88,95 \%$ CI 0.77 to 1.00 , $P=0.056$ ) (Figure 4). A fixed-effects model was used because heterogeneity between trials was not significant $\left(\mathrm{I}^{2}=0.0 \%, P=0.640\right)$.

\section{Safety}

Common drug-related adverse events were reported in all included trials. The majority were mild (grade 1) or moderate (grade 2) in severity. The focus of our analysis is grade 3 or 4 adverse events, which are listed in Table 2. Incidences of neutropenia and neutropenic fever were fewer with capecitabine-based chemotherapy compared with capecitabine-free chemotherapy (RR $0.59,95 \% \mathrm{CI}$ 0.39 to $0.89, P=0.012$; RR $0.50,95 \%$ CI 0.35 to 0.70 , $P<0.0001$, respectively). Incidences of anaemia and thrombocytopenia were not significantly different between the two groups. When comparing non-haematological adverse events, significantly more grade $3-4$ vomiting, diarrhoea and hand-foot syndrome occurred in the capecitabine-based chemotherapy group (RR 4.47, 95\%
CI 2.21 to $9.03, P<0.0001$; RR 2.86, 95\% CI 1.754 .68 , $P=0.0001$; RR $12.4,95 \%$ CI 3.6 to $42.8, P<0.0001$, respectively). However, there were no statistically significant differences in nausea, fatigue, cardiotoxicity or mucositis/stomatitis between the two arms.

\section{Publication bias}

Begg's and Egger's tests were used to assess publication bias. No publication bias was found for PFS, OS or ORR $(P=0.804, P=0.804$ and $P=0.216$, respectively).

\section{DISCUSSION}

Most clinical trials of first-line chemotherapy for advanced or metastatic breast cancer focus on intensive regimens. According to current guidelines, anthracyclineand taxane-based regimens are the standard primary chemotherapy for advanced or metastatic breast cancer $[19,20]$. However, intensive regimes maybe unsuitable for older women or patients who have significant complications. Capecitabine-based chemotherapy used as a treatment strategy in patients pre-treated with anthracycline or taxanes in general. According the guidelines of the European School of Oncology and the European Society for Medical Oncology (ESO-ESMO) 2014 [4], capecitabine was recommended as an option for the firstline treatment of advanced or metastatic breast cancer. 


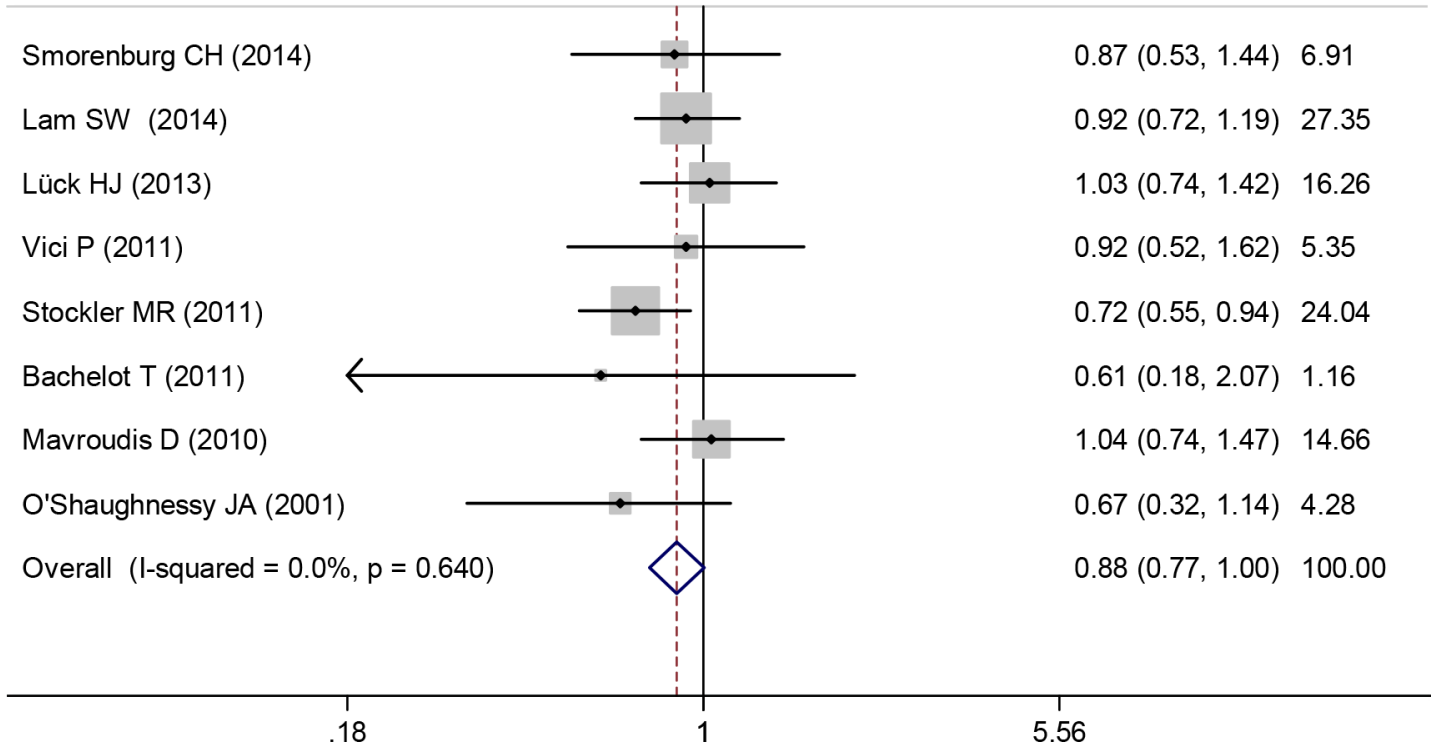

Figure 4: Overall survival of capecitabine-based chemotherapy versus capecitabine-free chemotherapy.

Table 2: Outcomes of grade 3 or 4 drug-related adverse events for capecitabine-based chemotherapy versus capecitabine-free chemotherapy

\begin{tabular}{|c|c|c|c|c|c|}
\hline \multirow[t]{2}{*}{ Adverse events } & \multirow[t]{2}{*}{ Trials } & \multirow[t]{2}{*}{ RR and $95 \% C I$} & \multirow[t]{2}{*}{$P$ value } & \multicolumn{2}{|c|}{ Heterogeneity } \\
\hline & & & & I2 & $P$ value \\
\hline Anemia & 7 & $0.86(0.46-1.60)$ & 0.641 & 0 & 0.475 \\
\hline Neutropenia & 8 & $0.59(0.39-0.89)$ & 0.012 & 86.3 & $<0.0001$ \\
\hline Thrombocytopenia & 7 & $0.95(0.48-1.88)$ & 0.878 & 0 & 0.889 \\
\hline Neutropenic fever & 7 & $0.50(0.35-0.70)$ & $<0.0001$ & 38.3 & 0.137 \\
\hline Nausea & 8 & $1.54(0.77-3.11)$ & 0.225 & 0 & 0.953 \\
\hline Vomiting & 7 & $4.47(2.21-9.03)$ & $<0.0001$ & 45.7 & 0.101 \\
\hline Diarrhea & 9 & $2.86(1.75-4.68)$ & 0 & 0 & 0.656 \\
\hline Fatigue & 6 & $0.96(0.59-1.57)$ & 0.883 & 21.7 & 0.271 \\
\hline Cardiotoxicity & 6 & $1.36(0.86-2.18)$ & 0.2 & 0 & 0.715 \\
\hline Hand-foot syndrome & 9 & $12.4(3.6-42.8)$ & $<0.0001$ & 57.2 & 0.017 \\
\hline Mucositis/stomatitis & 9 & $1.02(0.31-3.34)$ & 0.976 & 59.3 & 0.022 \\
\hline
\end{tabular}


Our study's pooled analysis indicates that capecitabine-based chemotherapy is significantly superior to capecitabine-free chemotherapy in terms of ORR and PFS, but that OS is similar between the two groups. This meta-analysis summarises the current randomised controlled trial evidence of the potential benefit of capecitabine-based chemotherapy as first-line treatment for the patients with advanced or metastatic breast cancer. The effects could be explained by capecitabine's synergistic effect with cytotoxic drugs through increased thymidine phosphorylase levels in tumours [20].

Most of the trials included in this review used a dose of capecitabine of $1,000 \mathrm{mg} / \mathrm{m}^{2}$ twice daily (on days $1-14$ of a 3-week cycle), which is lower than that approved by the USA Food and Drug Administration (1,250 mg/ $\mathrm{m}^{2}$ twice daily). This lower dose has been shown to lead to better tolerability of the drug without compromising its efficacy [21]. Lower haematological toxicity and higher gastrointestinal toxicity were seen in patients receiving capecitabine-based chemotherapy. It is worth noting that the rate of hand-foot syndrome toxicity was significantly higher in the capecitabine-based group. In the OMEGA study involving female patients aged $\geq 65$ years, capecitabine showed acceptable tolerance as first-line chemotherapy, even in vulnerable patients and those aged $\geq 75$ years [22]. A number of studies are also investigated novel dosing schedules of capecitabine. A 4-week schedule (days 1-21, every 28 days) of capecitabine-based therapy is widely used in Japan, and the ' $7 / 7$ ' regimen ( 7 days of therapy followed by 7 days of rest) is common in the United States [23-25]. Study has shown that apecitabinebased patients were significantly more likely to continue therapy beyond 6 months and 12 months than classical cyclophosphamide, methotrexate, and fluorouracil (CMF regimen) patients [26].

Approximately $20 \%$ of patients with metastatic breast cancer have human epidermal growth factor receptor 2 (HER-2)-positive tumours. These patients typically have a poor prognosis, with shortened PFS and OS usually $[17,27]$. Trastuzumab combined with docetaxel is a standard first-line chemotherapy regime for HER-2 positive metastatic breast cancer. One trial included in this meta-analysis compared capecitabine plus trastuzumab and docetaxel with docetaxel plus trastuzumab in HER-2 positive metastatic breast cancer. A high ORR was observed between both treatment groups and PFS was significantly longer in the capecitabine-based arm [17]. Another trial demonstrated that capecitabine combined with trastuzumab improved time to progression and ORR significantly when compared with capecitabine monotherapy in patients with progression after trastuzumab-based therapy [28]. Therefore capecitabine combination therapy may be a useful treatment option for patients with HER-2 positive metastatic breast cancer, although more evidence is needed.
Several limitations need to be considered when interpreting our analysis. First, all trials except one [16] involved patients with HER-2 negative tumours. We were not able to do a subgroup analysis by HER-2 status because of the lack of sufficient data. Second, the control regimens varied widely between included trials and this may have influenced the results. Third, the sample size is relatively small. A study with a large sample size is needed in the future to better understand the role of capecitabinebased regimens in the first-line treatment of advanced breast cancer.

In summary, this analysis indicates that capecitabinebased regimens produce superior ORRs and prolong the PFS of patients with advanced or metastatic breast cancer. In addition, it has been shown that tolerability can be improved through adjusting the dosing regimen of capecitabine. Therefore, capecitabine-based chemotherapy could be a preferable option as first-line therapy for patients with advanced or metastatic breast cancer. Further research is necessary to confirm these findings.

\section{MATERIALS AND METHODS}

\section{Search strategy}

Two investigators (YWJ and PGSH) independently carried out a systematic search from January 1998 to May 2015, using PubMed, EMBASE and the Cochrane Library database. We also reviewed the meeting abstracts of the American Society of Clinical Oncology (ASCO) and the European Society for Medical Oncology (ESMO) for the last 10 years. Searches were limited to human clinical trials published in English. The key words were capecitabine, Xeloda, breast cancer, breast neoplasm and first-line.

\section{Selection criteria}

Eligible studies had to meet the following inclusion criteria: randomised controlled trials involving patients with advanced or metastatic breast cancer; studies comparing capecitabine-based chemotherapy versus other chemotherapy as first-line treatment.

\section{Data extraction}

Two investigators (YWJ and GSG) extracted data independently, using a prepared information form. Any disagreement was discussed and resolved by consensus in a meeting with a third investigator. The following data were extracted from included studies: authors, publication year, study phase, number of intention-to-treat patients, treatment regimens, randomisation method, and the results of ORR, PFS, OS and adverse events. We contacted the corresponding authors to obtain additional information that was not reported in the articles. The quality of the 
randomised controlled trials included in the meta-analysis was evaluated using the Jadad scoring system using the measures of method of randomisation, double-blinding procedure, method of allocation concealment, and withdrawals [10].

\section{Statistical analysis}

The analysis was carried out using Stata 12.0 software, on an intention-to-treat basis. We calculated the HR for PFS and OS. The relative risk was used to calculate the ORRs and grade 3 and 4 drug-related adverse events. The HRs and their 95\% CIs were obtained from the articles directly, and we extracted data from the Kaplan-Meier survival curve as reported by Parmar et al. [11] if the value was not given in the article. The heterogeneity of study outcomes was assessed by the $\chi^{2}$ test or $\mathrm{I}^{2}$ statistics. Heterogeneity was considered statistically significant when the $\mathrm{P}$ value was $<0.05$ or $\mathrm{I}^{2}$ was $>50 \%$. If significant heterogeneity existed, data was analysed using a random-effects model; otherwise, a fixed-effects model was used.

\section{CONFLICTS OF INTEREST}

The authors have no conflicts of interest to disclose.

\section{REFERENCES}

1. Wolff AC, Hammond ME, Schwartz JN, Hagerty KL, Allred DC, Cote RJ, Dowsett M, Fitzgibbons PL, Hanna WM, Langer A, McShane LM, Paik S, Pegram MD, et al. American Society of Clinical Oncology/College of American Pathologists guideline recommendations for human epidermal growth factor receptor 2 testing in breast cancer. Arch Pathol Lab Med. 2007; 131:18-43.

2. Torre LA, Bray F, Siegel RL, Ferlay J, Lortet-Tieulent J, Jemal A. Global cancer statistics. CA Cancer J Clin. 2012; 65:87-108.

3. Aebi S, Gelber S, Anderson SJ, Lang I, Robidoux A, Martin M, Nortier JW, Paterson AH, Rimawi MF, Canada JM, Thurlimann B, Murray E, Mamounas EP, et al. Chemotherapy for isolated locoregional recurrence of breast cancer (CALOR): a randomised trial. Lancet Oncol. 15:156-163.

4. Cardoso F, Costa A, Norton L, Senkus E, Aapro M, Andre F, Barrios CH, Bergh J, Biganzoli L, Blackwell KL, Cardoso MJ, Cufer T, El Saghir N, et al. ESO-ESMO 2nd international consensus guidelines for advanced breast cancer (ABC2)dagger. Ann Oncol. 25:1871-1888.

5. Reichardt P, Von Minckwitz G, Thuss-Patience PC, Jonat W, Kolbl H, Janicke F, Kieback DG, Kuhn W, Schindler AE, Mohrmann S, Kaufmann M, Luck HJ.
Multicenter phase II study of oral capecitabine (Xeloda(")) in patients with metastatic breast cancer relapsing after treatment with a taxane-containing therapy. Ann Oncol. 2003; 14:1227-1233.

6. Pallis AG, Boukovinas I, Ardavanis A, Varthalitis I, Malamos N, Georgoulias V, Mavroudis D. A multicenter randomized phase III trial of vinorelbine/gemcitabine doublet versus capecitabine monotherapy in anthracycline- and taxane-pretreated women with metastatic breast cancer. Ann Oncol. 23:1164-1169.

7. Chan S, Romieu G, Huober J, Delozier T, TubianaHulin M, Schneeweiss A, Lluch A, Llombart A, du Bois A, Kreienberg R, Mayordomo JI, Anton A, Harrison M, et al. Phase III study of gemcitabine plus docetaxel compared with capecitabine plus docetaxel for anthracycline-pretreated patients with metastatic breast cancer. J Clin Oncol. 2009; 27:1753-1760.

8. Oshaughnessy JA, Blum J, Moiseyenko V, Jones SE, Miles D, Bell D, Rosso R, Mauriac L, Osterwalder B, Burger HU, Laws S. Randomized, open-label, phase II trial of oral capecitabine (Xeloda) vs. a reference arm of intravenous CMF (cyclophosphamide, methotrexate and 5-fluorouracil) as first-line therapy for advanced/metastatic breast cancer. Ann Oncol. 2001; 12:1247-1254.

9. Smorenburg $\mathrm{CH}$, de Groot SM, van Leeuwen-Stok AE, Hamaker ME, Wymenga AN, de Graaf H, de Jongh FE, Braun JJ, Los M, Maartense E, van Tinteren H, Nortier JW, Seynaeve C. A randomized phase III study comparing pegylated liposomal doxorubicin with capecitabine as firstline chemotherapy in elderly patients with metastatic breast cancer: results of the OMEGA study of the Dutch Breast Cancer Research Group BOOG. Ann Oncol. 25:599-605.

10. Jadad AR, Moore RA, Carroll D, Jenkinson C, Reynolds DJ, Gavaghan DJ, McQuay HJ. Assessing the quality of reports of randomized clinical trials: is blinding necessary? Control Clin Trials. 1996; 17:1-12.

11. Parmar MK, Torri V, Stewart L. Extracting summary statistics to perform meta-analyses of the published literature for survival endpoints. Stat Med. 1998; 17:2815-2834.

12. Luck HJ, Du Bois A, Loibl S, Schrader I, Huober J, Heilmann V, Beckmann M, Stahler A, Jackisch C, Hubalek M, Richter B, Stickeler E, Eidtmann H, et al. Capecitabine plus paclitaxel versus epirubicin plus paclitaxel as first-line treatment for metastatic breast cancer: efficacy and safety results of a randomized, phase III trial by the AGO Breast Cancer Study Group. Breast Cancer Res Treat. 139:779-787.

13. Lam SW, de Groot SM, Honkoop AH, Jager A, ten Tije AJ, Bos MM, Linn SC, van den Bosch J, Kroep JR, Braun JJ, van Tinteren $H$, Boven E. Paclitaxel and bevacizumab with or without capecitabine as first-line treatment for HER2negative locally recurrent or metastatic breast cancer: a multicentre, open-label, randomised phase 2 trial. Eur J Cancer. 50:3077-3088. 
14. Vici P, Giotta F, Di Lauro L, Sergi D, Vizza E, Mariani L, Latorre A, Pizzuti L, D’Amico C, Giannarelli D, Colucci G. A multicenter phase II randomized trial of docetaxel/ gemcitabine versus docetaxel/capecitabine as first-line treatment for advanced breast cancer: a Gruppo Oncologico Italia Meridionale study. Oncology. 81:230-236.

15. Stockler MR, Harvey VJ, Francis PA, Byrne MJ, Ackland SP, Fitzharris B, Van Hazel G, Wilcken NR, Grimison PS, Nowak AK, Gainford MC, Fong A, Paksec L, Sourjina T, Zannino D, Gebski V, Simes RJ, Forbes JF, Coates AS. Capecitabine versus classical cyclophosphamide, methotrexate, and fluorouracil as first-line chemotherapy for advanced breast cancer. J Clin Oncol. 29:4498-4504.

16. Bachelot T, Bajard A, Ray-Coquard I, Provencal J, Coeffic D, Agostini C, Boisseau M, Kaphan R, Dramais D, Oprea C, Ferri-Dessens RM, Guastalla JP, Perol D. Final results of ERASME-4: a randomized trial of first-line docetaxel plus either capecitabine or epirubicin for metastatic breast cancer. Oncology. 80:262-268.

17. Wardley AM, Pivot X, Morales-Vasquez F, Zetina LM, de Fatima Dias Gaui M, Reyes DO, Jassem J, Barton C, Button P, Hersberger V, Torres AA. Randomized phase II trial of first-line trastuzumab plus docetaxel and capecitabine compared with trastuzumab plus docetaxel in HER2-positive metastatic breast cancer. J Clin Oncol. 28:976-983.

18. Mavroudis D, Papakotoulas P, Ardavanis A, Syrigos K, Kakolyris S, Ziras N, Kouroussis C, Malamos N, Polyzos A, Christophyllakis C, Kentepozidis N, Georgoulias V. Randomized phase III trial comparing docetaxel plus epirubicin versus docetaxel plus capecitabine as first-line treatment in women with advanced breast cancer. Ann Oncol. 21:48-54.

19. Tryfonidis K, Senkus E, Cardoso MJ, Cardoso F. Management of locally advanced breast cancer-perspectives and future directions. Nat Rev Clin Oncol. 12:312.

20. Kurosumi M, Tabei T, Suemasu K, Inoue K, Kusawake T, Sugamata N, Higashi Y. Enhancement of immunohistochemical reactivity for thymidine phosphorylase in breast carcinoma cells after administration of docetaxel as a neoadjuvant chemotherapy in advanced breast cancer patients. Oncol Rep. 2000; 7:945-948.
21. Leonard R, Hennessy BT, Blum JL, O'Shaughnessy J. Dose-adjusting capecitabine minimizes adverse effects while maintaining efficacy: a retrospective review of capecitabine for metastatic breast cancer. Clin Breast Cancer. 11:349-356.

22. Zielinski C, Gralow J, Martin M. Optimising the dose of capecitabine in metastatic breast cancer: confused, clarified or confirmed? Ann Oncol. 21:2145-2152.

23. Gajria D, Gonzalez J, Feigin K, Patil S, Chen C, Theodoulou M, Drullinsky P, D'Andrea G, Lake D, Norton L, Hudis CA, Traina TA. Phase II trial of a novel capecitabine dosing schedule in combination with lapatinib for the treatment of patients with HER2-positive metastatic breast cancer. Breast Cancer Res Treat. 131:111-116.

24. Gajria D, Feigin K, Tan LK, Patil S, Geneus S, Theodoulou M, Norton L, Hudis CA, Traina TA. Phase 2 trial of a novel capecitabine dosing schedule in combination with bevacizumab for patients with metastatic breast cancer. Cancer. 117:4125-4131.

25. Kusama M, Nomizu T, Aogi K, Yoshimoto M, Horikoshi N, Tabei T, Noguchi S, Miura S, Yoshimura N, Kimura M, Toyama K, Shin E. Phase II study of 4-weekly capecitabine monotherapy in advanced/metastatic breast cancer. Breast Cancer. 17:233-240.

26. O'Shaughnessy JA, Kaufmann M, Siedentopf F, Dalivoust P, Debled M, Robert NJ, Harbeck N. Capecitabine monotherapy: review of studies in first-line HER-2-negative metastatic breast cancer. Oncologist. 17:476-484.

27. Slamon DJ, Clark GM, Wong SG, Levin WJ, Ullrich A, McGuire WL. Human breast cancer: correlation of relapse and survival with amplification of the HER-2/neu oncogene. Science. 1987; 235:177-82.

28. Von Minckwitz G, du Bois A, Schmidt M, Maass N, Cufer T, de Jongh FE, Maartense E, Zielinski C, Kaufmann M, Bauer W, Baumann KH, Clemens MR, Duerr R, et al. Trastuzumab beyond progression in human epidermal growth factor receptor 2-positive advanced breast cancer: a german breast group 26/breast international group 03-05 study. J Clin Oncol. 2009; 27:1999-2006. 